\title{
Marketing Strategy, Social Responsibility, and Value Chain in the Agri-food System
}

\author{
Filippo Sgroi \\ Department of Agricultural, Food and Forestry Sciences, University of \\ Palermo, Palermo 90128, Italy
}

\section{Enrica Donia}

Department of Economics, Business and Statistics, University of Palermo, Palermo 90128, Italy

\section{Mário Franco \\ Department of Management and Economics, University of Beira Interior, 6200-209 Covilhã, Portugal}

\section{Angelo Marcello Mineo \\ Department of Economics, Business and Statistics, University of Palermo, Palermo 90128, Italy}

Additional index words. business competitiveness, creation of value, economic performance

\begin{abstract}
The agri-food sector has changed significantly over the years, moving from a simple production system to a more and more industrialized one. For agents/operators involved in this sector, ensuring product quality and environmental externalities has become the key point to gaining a competitive advantage. In this context, corporate social responsibility (CSR) fits perfectly. This study analyzes the influence of CSR practices on the economic performance of a random sample of 130 agri-food companies in Italy. The results of an analysis of multiple linear regression models show that the economic performance (measured through value added and income) of agri-food enterprises seems to be influenced statistically by workplace CSR practices. Analysis of another model, during which we studied the relationship between income and the CSR practices (independent variables), highlights that operating results (economic performance) can be improved by CSR practices regarding the workplace, environment, and local community. Thus, empirical evidence shows that some CSR practices have positive effects on economic performance, with several implications for theory and practice.
\end{abstract}

The concept of an agri-food system (AFS) is much more complex than is commonly believed. In the past, it was mainly associated with the agricultural sector, but in recent times, the physiognomy of the sector has changed radically. Technological and organizational changes have affected the production, distribution, and consumption of agricultural

Received for publication 1 Nov. 2019. Accepted for publication 15 Nov. 2019.

Published online 10 January 2020.

We gratefully acknowledge financial support from National Funds of the FCT-Portuguese Foundation for Science and Technology for the project UID/ $\mathrm{ECO} / 04007 / 2019$. We thank the anonymous reviewers for their very helpful comments that contributed to the development of this article.

F.S. is an Associate Professor of Agricultural Economics.

E.D. is a Researcher of Agricultural Economics. M.F. has a PhD in Management.

A.M.M. is a Full Professor of Statistics.

F.S. is the corresponding author. E-mail: filippo. sgroi@unipa.it.

This is an open access article distributed under the CC BY-NC-ND license (https://creativecommons.org/ licenses/by-nc-nd/4.0/).
(Hartmann, 2011). Years ago, a focus on maximizing profits brought about mass production - that is, the standardization of products. Although this production model was suitable for the past, today, a consumer segment with a medium-to-high income is also attentive to the intangible attributes that food products transmit (Luhmann and Theuvsen, 2016; Mohr and Webb, 2005; Romani et al., 2016). CSR responds to these needs (Belu and Manescu, 2013; Jean et al., 2018). CSR is defined here in relation to the value and quality of products, their relationship with the land, the production processes underlying them, governance structures, the definition of business strategies, and, last, businesses' ability to convey an image compatible with consumers' values and principles.

Few studies have focused on the role of CSR practices in the economics and finances of agri-food firms. There has been a concomitant failure to define the multidimensional concepts of CSR, AFS, and performance, because these have only been measured through indicators connected to business without considering other important dimensions, such as the environment, workplace, and local community. Becchetti et al. (2014) emphasize that companies traditionally oriented to profit maximization, can also attenuate the social and environmental externalities of their action today. This study aims to analyze the influence of CSR practices on the economic performance (measured by value added and income variables) of agrifood companies in Italy. It aims to contribute to entrepreneurial practice. Empirical evidence suggests that for companies to maximize profits, they should increase, of their own volition, attention to the social and environmental externalities of their actions, while recognizing the need to demonstrate that greater social responsibility will not put them out of business.

The remainder of this article is organized as follows: First, there is a brief literature review of agri-food systems and CSR practices and their contribution to firms' performance. This discussion is followed by a presentation of the methodology and research method of our study (sample selection, and data collection and analysis). The results with subsequent discussion are then presented. Last, the conclusions of the studies are summarized, together with their implications and future lines of research.

\section{Literature Review and Hypothesis Development} the consumer was often also a producer and therefore had sufficient information regarding production and processing methods.

Product quality can impact directly or indirectly the health and safety of consumers. Therefore, it is important for food companies to produce clear signs of good quality. Among the most common ones are guarantees, trademarks, labels, legal responsibility, different forms of certification, etc. In fact, these are the instruments belonging to a company's strategy for social responsibility
AFS as context of study. The AFS has changed significantly over the years, moving from a simple production system to a more and more industrialized one. On the demand side, customers indicate they need clarity and transparency regarding the food products they consume. On the other hand, as far as companies are concerned, it has become fundamental to transmit a message of safety to their customers and guarantee the quality of products for sale. 
Compared with the past, today's agri-food sector incorporates several new needs, features, and functions that foods must have (Belletti et al., 2015). If the consumer used to be almost exclusively attentive to product attributes (such as nutrition, organoleptic characteristics, shape attributes, etc.), nowadays increasing attention is paid to process attributes (such as genuineness, absence of sophistication, ties with the local area, traditional production techniques, respect for the environment, biological production processes, animal welfare, corporate social responsibility, fairness and respect for working conditions, etc.). Indeed, the demand for food products seems to have shifted from differentiated goods to those goods understood as baskets of characteristics (Quiñones-Ruiz et al., 2016).

In this sense, attention has shifted from the good itself toward the attributes (or characteristics) that define it. According to this method of analysis, known as the multidimensional approach, what is relevant are the attributes a good possesses. It follows that consumer demand is not addressed to a good in itself, as part of a given commodity category, but is directed to the specific set, or basket, of characteristics that distinguishes it (Tregear et al., 2016). Starting from these assumptions, we can define the quality of a food product as "a set of characteristics or attributes that are able to satisfy the needs of consumers, who can derive different benefits from goods which are considered similar" (Lancaster, 1966).

In addition, the quality level varies according to the characteristics and value that consumers attribute to individual qualities. A different orientation, or rather a hierarchical approach (Zeithaml, 1988) - unlike the multidimensional one - does not focus on product attributes, but on the association between them and the most abstract category: values. This method of analysis is based on the assumption that consumers organize information on products at various levels of abstraction, from simple product attributes to more abstract personal values.

In a situation in which they are not always necessarily informed about the goods purchased, consumers are asked to make choices under conditions of uncertainty (Gaviglio et al., 2016). It can be said that, as the visibility of attributes to consumers decreases, problems related to the lack of information and uneven distribution of the available information become increasingly important, so CSR and its tools fit perfectly into these contexts.

CSR in the Agri-food sector. The first significant contribution on social responsibility can be attributed to Bowen who, in the 1950 s, defined social responsibility from the point of view of a "businessman" (Bowen and Johnson, 1953). This contribution, although focused on the individual responsibility of managers rather than the responsibility of the company as a whole, had the merit of recognizing companies as vital power centers, highlighting how their actions are able to affect the life of a society.
In particular, Bowen initially defined social responsibility as: "The duty to pursue those policies, make those decisions, or follow those lines of conduct which are desirable in relation to the objectives and values recognized by society" (Bowen and Johnson, 1953).

Given the vast range of such studies, in recent years, the concept of CSR has acquired different senses and meanings (Belu and Manescu, 2013). The multitude of definitions, on the one hand, highlights the modernity of the theme, but also the existence of different conceptions and interpretations, on the other. Among them, nowadays we tend to highlight the strategic vision of CSR (Kitzmueller and Shimshack, 2012; Lockett et al., 2006). In fact, CSR can be considered a business strategy that allows the creation of value in the medium to long term by leveraging a proper relationship with stakeholders (Maloni and Brown, 2006; Maroušek et al., 2014; Smith and Langford 2009; Vlachos et al., 2009).

However, beyond the definitions and interpretations, being socially responsible has become a necessity for those companies that do not want to run the risk of being excluded from the market. The health problems related to nutrition have led to a change in the relationship between the consumer and the agri-food market. In particular, the consumer has developed more and more sensitivity not only toward issues such as food safety, the environment, animal welfare, and biodiversity, but also toward the ethical values of consumption and respect for human rights and workers (Becker-Olsen et al., 2006; Belu and Manescu, 2013).

Furthermore, the market for agri-food products has become global. The importation of products - the production, distribution, and consumption of which follow regulations different from those of the European Unionmay have adverse effects on consumer health. Indeed, in relation to agricultural and agrifood enterprises, CSR should be a natural orientation because it can become an element of qualification and distinction from other market actors (both national and international) operating with inadequate standards.

Thanks to CSR, consumer trust becomes an intangible factor, which is able to give value to the company. Subjects operating in the agri-food sector have a great opportunity: Through implementing proper strategies, they can give their business added value compared with their competitors and, therefore, ultimately obtain a competitive advantage.

In this context, the possibility of an agrifood company growing and orienting itself more and more toward CSR is a challenge full of complexity, but it also represents that winning element that can contribute to the company's growth and social and economic development, its supply chain, and, ultimately, to its own local area and community. CSR becomes a strategy for creating value based on the new needs of a market segment that is increasingly attentive to the intangible aspects of food products.
The ethics problems the entrepreneur should have toward the environment should not be underestimated. An entrepreneur, who respects the environment, creates those conditions of growth and development that allow to create competitive advantage for the company and the territory.

CSR and economic performance: Hypothesis. During the past few decades, business performance has become increasingly monitored, and it is now widely perceived that companies should take a deeper responsibility to ensure greater benefits (Brammer and Millington, 2004, Jean et al., 2018). Thus, Wang et al. (2012) investigated the relationship between CSR and company performance.

CSR has now become a necessary and fundamental approach for any type of company, and, in particular, for agri-food companies. The implementation of such strategies means obtaining different benefits in terms of competitiveness. It is also possible to establish some moments of innovation, which contribute to development, not only of the company itself, but also indirectly to society as a whole.

A strategic approach to CSR has become increasingly important for company performance. Being more responsible can bring benefits in terms of risk management, cost reduction, capital access, customer relationships, human resource management, and capacity for innovation. By meeting their social responsibilities, agri-food companies create long-term trust among workers, consumers, and citizens. High levels of trust also contribute to determining a context in which these companies can innovate and grow. Nowadays we can observe how the adoption of CSR initiatives affect company performance positively. According to some research (e.g., Zamagni, 2013), CSR has positive effects mainly on six factors that influence company performance and competitiveness: costs, human resources, consumer perspectives, ability to innovate, risk and reputation management, and economic and financial performance.

According to Margolis and Walsh (2003), by studying a sample of companies between 1972 and 2003, a tendency to identify a positive relationship between CSR and the responsible management strategy is shown. As noted by the authors, such evidence would alleviate the concerns of those who affirm there is no link, supporting the hypothesis that CSR strategies can increase and improve economic results.

Orlitzky et al, (2003) reported that the "meta-analysis" carried out in the research correlating a sample of 33,878 observations showed a positive association between CSR and economic and financial performance. Based on the results obtained, they argued that the different degrees of positivity detected are caused by contingent factors, such as reputational effects, or are linked to methods of measuring economic performance.

Siegel and Vitaliano (2007) performed an empirical investigation concerning the 
determinants of strategic CSR and also reported evidence of economic benefits derived from strategic CSR. Porter and Kramer (2006) made a strong case for CSR practices, arguing that companies should favor a strategic approach to CSR (i.e., they should identify the corporate agenda that can bring the greatest competitive benefit).

Wang et al. (2012) argued that when a company makes efforts to fulfil its social responsibility, it will improve its corporate image, which helps corporate sales as well as firm performance. Their study found that when a firm endeavors to fulfill its CSR, this has a positive impact on firm performance in terms of operating efficiency, corporate value, and stock return.

After more than 30 years of investigating and analyzing the relationship between CSR practices and economic performance, this field of research still seems to be open and no conclusion has yet been reached that shows a good degree of security relating to the results obtained. However, based on the overview of the aforementioned research, it can be said that the presence of a positive relationship between social and economic performance seems fairly certain. Therefore, the following central research hypothesis was formulated:

CSR practices affect positively the economic performance of companies in the agrifood sector.

\section{Materials and Methods}

Sample and data. To test the research hypothesis, a quantitative research design was adopted. For this purpose, a database of medium-large companies in the agri-food sector in Italy was built. To do so, data were gathered randomly through the Global Reporting Initiative (GRI) standards that these agri-food companies decided to publish. The criteria for defining medium-large companies in terms of their number of employees followed those established by the European Union Commission (2003).

From the overall population of companies registered in this reporting, a random sample of 130 companies operating in the Italian agri-food sector was selected. These companies operate in different areas of the agri-food sector: fish processing and conservation companies, fruit processing and preservation companies, oil production companies, dairy companies, bakery production companies, and companies in the beverage sector.

To examine bias, we set the characteristics of the initial population against the final sample. In doing so, the attributes of the 130 companies did not diverge in any systematic way from all companies in GRI [cf. also Blumberg et al. (2005)]. This holds true, in particular, for demographic characteristics such as company sector and size (number of employees), so that bias did not occur in our study. In addition, we performed a $t$ test (Armstrong and Overton, 1977) to compare the first and last waves of companies for each of the research variables, and this analysis also revealed no significant differences $(P<$ $0.01)$.

The data were collected from the sustainability reports prepared according to GRI standards. GRI takes into account the three dimensions of sustainabilityeconomic, environmental, and social - and for each of these dimensions, the GRI guidelines identify categories, aspects, and performance indicators. CSR is a multidimensional concept, which is an aspect of particular concern in this study. Multidimensionality implies that various distinct aspects of the nature of a business need to be considered simultaneously when assessing a company's CSR performance (Belu and Manescu, 2013). Thus, our independent variables (CSR practices) were measured from the GRI series indicators for each of the corresponding four areas of the CSR, following their classification. After that, some of the indicators considered most significant were selected for each series. To obtain an overview of what has been said so far, the connections made are reported in Table 1.

As far as the measurement of economic performance (dependent variable) is concerned, two different variables were taken into consideration: the economic value (value added) directly generated by the company's activities (in thousands of euros) and balance sheet data concerning the profit/loss for the year (in thousands of euros) for the years 2012, 2013, and 2014 (income). Subsequently, the average profit/loss of companies was taken into consideration.

In this way, the 10 variables for the "social measure" of the companies that were the object of measurement were obtained. They, as shown in Table 1, have been divided by scope and, using the data from the sustainability reports, were detected as follows: a) Environment

1. Electricity savings: First of all, energy consumption was taken for each company's electricity (GRI indicator EN3 in Table 1) for the years 2012, 2013, and 2014. Data collected were then converted to the same measurement unit (megaWatts). Energy savings was then calculated as the difference between consumption in year $n-1$ minus consumption in year $n$. Negative values of savings can be observed, indicating an increase in electricity consumption. The average electricity savings over the 3 years was then calculated. The data obtained in this way indicate that, the greater the savings, the more the company pays attention to environmental issues.

2. Water savings: Water was taken from the water supply (in cubic meters) (GRI indicator EN8 in Table 1) for the years 2012, 2013, and 2014. The savings in water was determined as the difference between the levy in year $n-1$ minus the withdrawal in year $n$. Also, in this case, negative savings values can be observed. The average water savings over the 3 years was then calculated. The greater the savings, the more a company is responsible for the environment.

3. Waste savings: Data on the tons of waste produced by the companies were collected (GRI indicator EN22 in Table 1) for the years 2012, 2013, and 2014. The savings were then calculated for waste produced as the difference between the tons produced in year $n-1$ less those produced in year $n$. The same applies to what has already been said for the negative values of savings. The final figure was then derived from the average savings of waste produced in 3 years. Obviously, less waste is produced the more a company is attentive to respecting the environment.

b) Work

4. Work data: Measures concerning the number of women working in companies, compared to the total number of workers (GRI indicator LA13 in Table 1). For each year, it we then identified the rate of female employment for the total number of workers by dividing the number of female workers by the total number of employees. The average employment rate for female workers was then determined. The companies that focus on equal opportunities should have a higher rate, and therefore social policies oriented to CSR.

5. Accident frequency: Data pertaining to the number of accidents at work were collected for each company along with the total hours worked per year. The rate of frequency of injuries was then calculated (GRI LA7 indicator in Table 1), which provides the frequency with which injuries occurred during working hours. The average rate of accident frequency was then determined. The more a company pays attention to worker safety, the lesser the accident frequency rate.

6. Employee training: For each company for the 3 years, data regarding the number of hours of professional training were acquired (GRI indicator LA10 in Table 1). Finally, the average number of training hours for each company was determined. The greater the number of training hours, the greater the attention the company paid to its employees.

c) Territory

7. Economic data: Data on the distribution of added value were acquired (in thousands of euros) (GRI indicator EC1 in Table 1) for the companies studied. These data include investments in the community in the form of donations, social sponsorships, etc. Data on the economic value 
Table 1. Measuring corporate social responsibility (CSR) and economic performance through Global Reporting Initiative (GRI) standards.

\begin{tabular}{|c|c|c|c|}
\hline CSR dimensions & Series of GRI indicators & Selected indicators for CSR practices & Model $\mathrm{R}$ variables \\
\hline \multirow[t]{3}{*}{ Environment } & \multirow{3}{*}{$\begin{array}{l}\text { Series of protocols and environmental } \\
\text { indicators (EN) }\end{array}$} & 1. Electricity consumption (EN3) & 1. Electricity savings \\
\hline & & 2. Water consumption (EN8) & 2. Water savings \\
\hline & & 3. Product waste (EN22) & 3. Waste savings \\
\hline \multirow[t]{3}{*}{ Work } & \multirow{3}{*}{$\begin{array}{l}\text { Series of protocols and indicators of } \\
\text { work practices and adequate working } \\
\text { conditions (LA) }\end{array}$} & 4. Diversity and equal opportunities (LA13) & 4. Work data \\
\hline & & 5. Health and safety at work (LA7) & 5. Accident frequency \\
\hline & & 6. Training and education (LA10) & 6. Employee training \\
\hline \multirow[t]{5}{*}{ Territory } & \multirow{5}{*}{$\begin{array}{l}\text { Series of protocols and economic } \\
\text { indicators }(\mathrm{EC})\end{array}$} & Economic performance (EC1) & \\
\hline & & 7. Donations and other investments in the community & 7. Economic data \\
\hline & & 8. Remuneration to employees & $\begin{array}{l}\text { 8. Value that companies have } \\
\text { invested in their employees }\end{array}$ \\
\hline & & Indirect economic impacts (EC8) & \\
\hline & & $\begin{array}{l}\text { 9. Commercial commitments, donations of } \\
\text { products/services, pro bono activities }\end{array}$ & $\begin{array}{l}\text { 9. Average number of sponsorships } \\
\text { and campaigns }\end{array}$ \\
\hline Product & $\begin{array}{l}\text { Series of protocols and product liability } \\
\text { indicators (PR) }\end{array}$ & $\begin{array}{l}\text { 10. Programs related to compliance with } \\
\text { laws, standards, and voluntary codes (PR6) }\end{array}$ & 10. Certifications \\
\hline
\end{tabular}

Source: Our adaptation of the GRI guidelines for sustainability reporting.

Table 2. Economic value.

\begin{tabular}{ll}
\hline Item & \multicolumn{1}{c}{ Comment } \\
a. Direct economic value generated & Net sales plus revenues from financial investments and sale of goods \\
b. Operating costs & Payments to suppliers, nonstrategic investments, royalties, and payment facilities \\
c. Compensation and benefits & Monetary expenses for employees (current payments, not future commitments) \\
d. Payments to capital providers & All payments to capital providers' firm \\
e. Payments to Public Administration & Taxes and gross taxes \\
f. Investments in the community & Voluntary contributions and investment of funds in the community (including donations) \\
\hline
\end{tabular}

generated and distributed were derived, when possible, from the financial statement operating certificates certified by external auditors. These data must be presented according to a specific scheme, as shown in Table 2. For the comun variable we took the value reported for $\mathrm{f}$ in Table 2 , whereas for the person variable we took the value reported for $\mathrm{c}$ in Table 2 . We then took the average of the 3 years observed to obtain the average added value redistributed to the community. The greater the amount of money reinvested, the more attention is paid to corporate social issues.

8. Value that companies have invested in their employees: For each company, the value of value distribution was taken added (GRI indicator EC1 in Table 1) that companies have invested in their own collaborators. This value also includes all benefits other than remuneration. The average value was then obtained for the 3 years under examination. The greater the value, the greater the attention paid to personnel.

9. Average number of sponsorships and campaigns: The average number of sponsorships and campaigns was determined for each company implementing social measures (GRI indicator EC8 in Table 1). The greater the value, the greater the commitment of the local business.

d) Product

10. Certifications: For each company, the number of certifications obtained for own products (GRI indicator PR6 in Table 1) was obtained. The num- ber includes social certifications, environment, quality, controlled supply chain, etc. The average value for 3 years was determined. The more product certifications companies boast, the more attention should be paid to the quality of the same.

The measurement of economic performance requires two different variables:

1. Value added: This is the economic value generated directly by the activity of the company (in thousands of euros). The reference data are the average values over 3 years of the added value produced by the company. This figure is important because it highlights the company's ability to generate wealth advantage of different stakeholders.

2. Income: For each company, Data on the financial statements were collected (profit and loss in thousands of euros) for the years 2012, 2013, and 2014. After that, the average profit/loss of companies was taken into consideration.

Data analysis. A regression analysis was used to explain the existing relation between a variable $Y$, called a response variable, and one or more variables called explanatory variables $\left(X_{1}, X_{2}, \ldots, X_{n}\right)$. In other words, we are looking for some kind of function like this:

$$
Y=f\left(X_{1}, X_{2}, \ldots, X_{n}\right)+\varepsilon,
$$

which indicates the existence of a functional link, on average, between the dependent variable (value added and income) and the explanatory variables (environment, work, territory, and product, all of which are CSR practices). Part of this link, however, is composed of an accidental, random, or erratic component. Although the first component of the equation represents the part of the response variable explained by the explanatory variables, the second component represents that part of the variability of the response that cannot be attributed to systematic or easily identifiable factors, but is a result of the case or different causes that have not been taken into consideration in the regressive model. The functional link can, theoretically, be of any type, but in practice it is preferable to use a linear function, so this is why we talk about a multiple linear regression or a linear model. This model has the following formulation:

$$
\mathrm{Y}=\beta_{0}+\beta_{1} * X_{1}+\ldots+\beta_{n} * X_{n}+\varepsilon,
$$

where $\beta 1, \ldots, \beta_{n}$ are called regression coefficients and are the parameters of the model to be estimated on the basis of sample observations, in addition to $\beta_{0}$.

To refine the analysis, it is often appropriate to reduce the number of variables used for model building. The advantage of reducing the data sets lies primarily in improving the model's accuracy. The work could benefit from the elimination of irrelevant or redundant variables.

For our data analysis, we decided to use principal component analysis (PCA) (Hotelling, 1933), a technique for simplifying data that is used in the field of multivariate statistics, to reduce the number of variables in the model without losing too much significance.

The software used for the analysis, and that has certainly proved to be appropriate for the 
Table 3. New data set on company performance resulting from the principal component analysis.

\begin{tabular}{|c|c|c|c|c|c|}
\hline \multicolumn{4}{|c|}{ CSR practices } & \multicolumn{2}{|c|}{ Economic performance } \\
\hline Employment & Environment & Territory & Product & Value added & Income/loss \\
\hline 182,461 & $-29,738.40$ & $369,529.30$ & 5 & $2,964,684$ & 325,193 \\
\hline $3,597.99$ & $10,009.84$ & $13,303.87$ & 9 & 37,330 & 6,746 \\
\hline 26,937 & $-309,772$ & $61,543.67$ & 9 & 611,500 & 9,534 \\
\hline 12,181 & $-4,652.04$ & $74,666.62$ & 5 & 125,301 & 7,185 \\
\hline $2,223.49$ & $9,934.864$ & $5,956.83$ & 6 & 11,292 & -121 \\
\hline $4,583.98$ & $-11,853$ & $15,568.38$ & 5 & 458,347 & 12,333 \\
\hline $1,401.99$ & $-6,302.82$ & $23,375.05$ & 3 & 39,204 & 561 \\
\hline $70,661.50$ & $21,116.79$ & $1,414,727$ & 5 & $2,415,500$ & 320,667 \\
\hline
\end{tabular}

Table 4. Regression analysis of the effect of corporate social responsibility practices on value added.

\begin{tabular}{|c|c|c|c|c|}
\hline \\
\hline Min. & $1 \mathrm{Q}$ & Median & $3 Q$ & Max. \\
\hline Coefficients & Estimate & SE & $t$ Value & $\operatorname{Pr}(>|t|)$ \\
\hline Work & $2.152 \mathrm{e}+01$ & $4.152 \mathrm{e}+00$ & 5.184 & $0.0008^{* * *}$ \\
\hline Environment & $2.217 \mathrm{e}+00$ & $2.532 \mathrm{e}+00$ & 0.876 & 0.4068 \\
\hline Territory & $3.132 \mathrm{e}-01$ & $6.218 \mathrm{e}-01$ & 0.504 & 0.6281 \\
\hline
\end{tabular}

Residual SE $=771,900$ on 8 degrees of freedom (df), multiple $R^{2}=0.8169$, adjusted $R^{2}=0.7254, \mathrm{~F}=8.926$ on 4 and $8 \mathrm{df}$, and $P$ value $=0.0048$.

$* * *$ Significant at $P<0.001$.

work, is called $R$ (R Core Team, 2013), an object-oriented programming language and a specific development environment for statistical data analysis (Bruno, 2013; Mineo, 2004).

\section{Results and Discussion}

To begin with, the individual dimensions of CSR (environment, work, territory, and product) used in this study were taken by building a single variable for each them, which was made up of the main components of the original variables. The data set, including all the observations regarding the variables that compose it, was loaded.

In PCA, it is necessary to use the covariance matrix, or the correlation matrix alternatively. Usually, if the data do not have large differences in terms of variance, covariance is used; otherwise, it is preferable to use the correlation because it is equivalent to using the covariance matrix on standardized data. In our case, there did not seem to be much difference between the variances, so it was preferable to work on the covariance matrix for the reasons just indicated.

The same can be done for the other practices of CSR. However, the product dimension has only one original variable, and therefore PCA was not performed. When the number of variables had been reduced from 10 to four (one for each domain), one became the core of the analysis by setting the regression models.

After reducing the number of CSR variables through PCA, we continued, using the same technique, by considering only one main component for each observed sector. The new data are presented in Table 3 . It was possible to use these values to determine two different regression models. For model 1, we wanted to investigate the link between the value added (economic performance) and the four independent variables (CSR practices) described earlier. In this model, we wanted to check whether the companies most involved in social responsibility practices have, on average, a greater value-added value. For model 2 , we studied the relationship between income and the four CSR practices (independent variables). In this case, we wanted to observe whether, on average, the companies that implemented CSR practices had greater economic returns.

Estimation of the parameters of a multiple regression model with $\mathrm{R}$ software was done using the $l m$ function. Estimating them allows testing some of the hypotheses previously formulated for the models. In particular, there was the hypothesis that the regression coefficients were significantly different from zero. For each model defined, the following hypothesis system occurred:

$H_{0}: \beta_{I}=0 \forall \mathrm{I}$-meaning, none of the social variables affect economic performance

$H_{1}: \beta_{\mathrm{I}} \neq 0$ for at least a $i$-meaning, at least one of the dimensions of CSR influences economic performance

Through $l m$, therefore, the value of Student's $t$ test, the relative $P$ value, and the degree of significance was determined for each regression coefficient, beginning from the software returns from its analysis of model 1 (Table 4).
In this case, it seems that work is the area of CSR with the most influence on added value, having reached a very high level of significance. Respect for working conditions, favors a positive organizational environment that has an impact on added value.

The part of the variance explained by the explanatory variables is, however, high, because the coefficient of determination was $R^{2}=0.82$. We can also verify the degree of correlation between value added and social variables. This, on $\mathrm{R}$, occurs through the core command, which returns the correlation matrix shown in Table 5.

Work correlates positively (0.89) with added value. Therefore, with the increase in social practices, the added value produced by agri-food companies increases their relationship to work.

Continuing the analysis, it is necessary to emphasize that, in general, the $t$ tests on the regression coefficients are not independent. In particular, the significance of the regression parameters can be established through another statistical test. Indeed, it is generally known that by increasing the number of explanatory variables of a model, the value of $R^{2}$ also increases. It is therefore necessary to establish whether the increase in $R^{2}$ can be considered significant. As a measure of the good explanation of the response variable given by the explanatory variables, it is possible to use Akaike's information criterion (AIC). A low AIC value corresponds to a good explanation of the response variable. Therefore, the right compromise between the minimum number of explanatory variables and the explanation 
Table 5. Correlation matrix.

\begin{tabular}{llcccc}
\hline Variables & \multicolumn{1}{c}{1} & 2 & 3 & 4 & 5 \\
\hline 1. Work & 1 & & & & \\
2. Environment & 0.0937 & 1 & 1 & & \\
3. Territory & 0.3537 & 0.1365 & -0.1258 & 1 & \\
4. Product & 0.0079 & -0.3236 & 0.3810 & 0.0976 & 1 \\
5. Value added & 0.8853 & 0.1836 & &
\end{tabular}
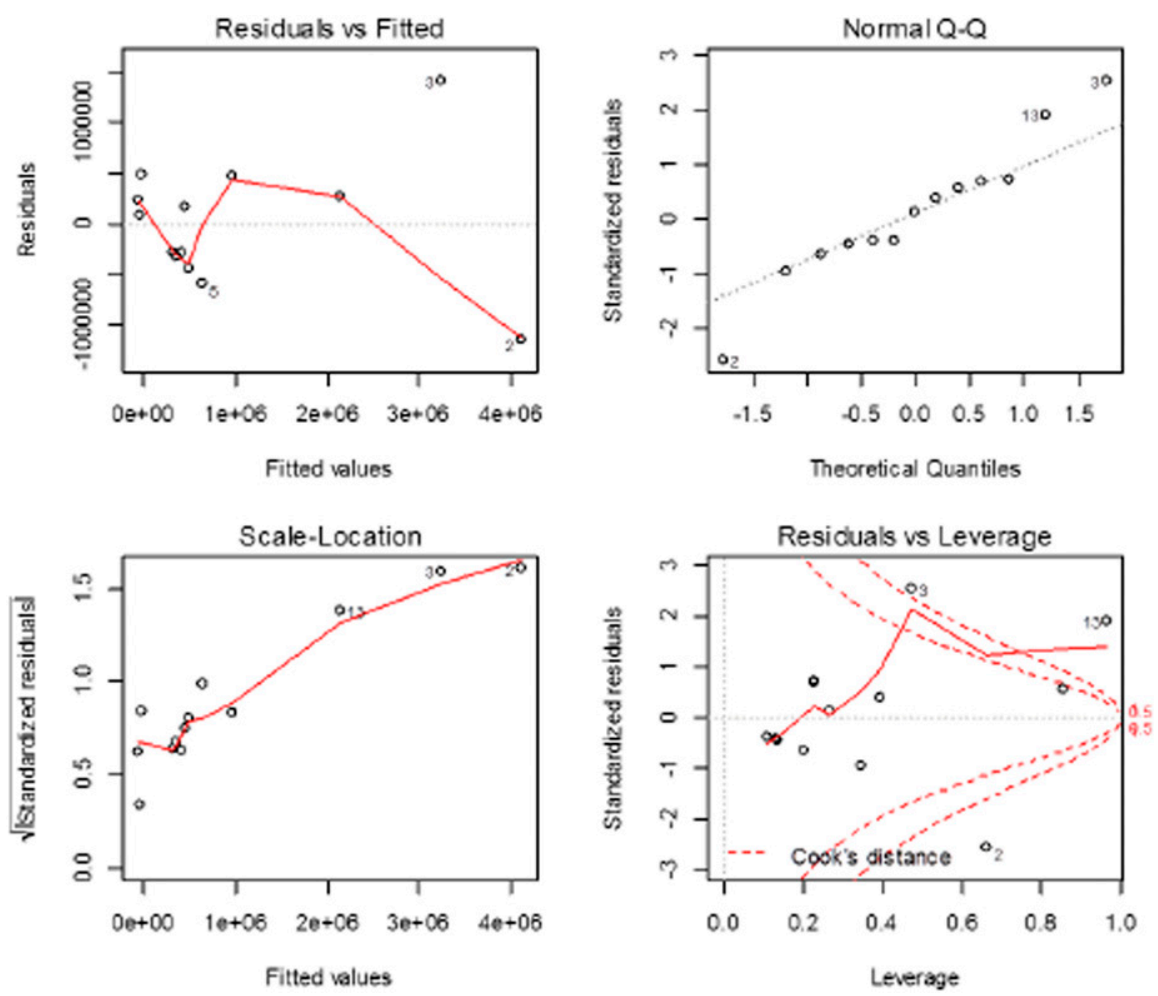

Fig. 1. Plot for the analysis of residuals on model 1. Link between the value added (economic performance) and the independent variables (corporate social responsibility practices).

Table 6. Regression analysis of the effect of corporate social responsibility practices on income.

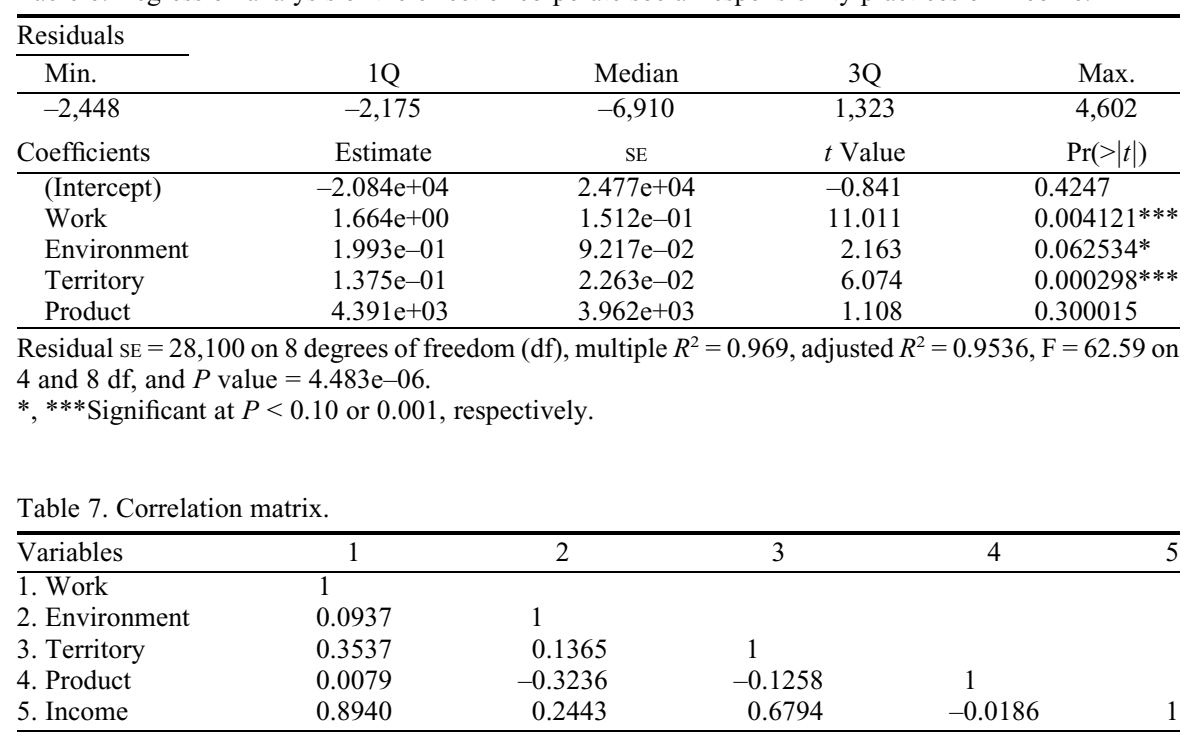

of the response variable is sought, based on the values of the AIC.

According to this procedure, the best model is the one with work explanatory variables only. As already seen in the com- suggested the elimination of the explanatory variables in question.

After estimating the model parameters and verifying the hypotheses made, it is necessary verify that some basic assumptions of the model are valid. Usually, basic hypotheses are made on the errors that must then be properly verified. Such hypotheses concern:

- The distribution of errors, which must be of a normal type

- Errors must have zero mean and constant variance (homoskedasticity)

- The fact that the errors are uncorrelated between them two by two

This analysis, known as residual analysis, is usually in graph form. In our case, we used a single graph to represent the entire analysis. In particular, the graph's quadrants give information on the hypotheses made about the errors, as can be seen in Fig. 1.

Based on Fig. 1, we can verify several hypotheses about accidental errors:

- In the first quadrant (top left), we can verify the hypothesis of error independence. In this case, there does not seem to be any strange behavior.

- In the second quadrant (top right), we can verify the hypothesis of error normality. In this case, the points seem to be placed in the vicinity of the line even if they are not exactly coincident.

- In the third quadrant (bottom left), the hypothesis of homoskedasticity (constant variance) can be verified. In this case, they do not seem to have a strange shape, so the hypothesis seems to be respected.

- In the fourth quadrant (bottom right), we can see the presence of some anomalous values. The data seem to be mostly grouped, except for some values $(13,2$, and 3 ) that seem to be out of the scheme.

In general, the basic assumptions about errors seem to be respected and so the results of this first model can reasonably be taken into consideration.

After repeating the analysis performed so far for model 2, we calculated the regression coefficients that gave the results shown in Table 6 . In this case, the $t$ test statistic shows how work and territory are the areas of CSR with the most influence on the operating result. Even the environment seems to play its part, because it has reached a good level of significance. The part of the variance explained by the explanatory variables is, however, very high; the coefficient of determination is $R^{2}=0.97$.

The degree of correlation between profit/loss for the year and social variables can then be verified through the correlation matrix (Table 7).

Work (0.89) and territory (0.68) are the areas correlated most positively to the operating result (income). Therefore, following an increase in CSR practices in terms of work and territory, the profits of agri-food companies should also improve. Porter and Kramer (2006) make a strong case for CSR practices, 

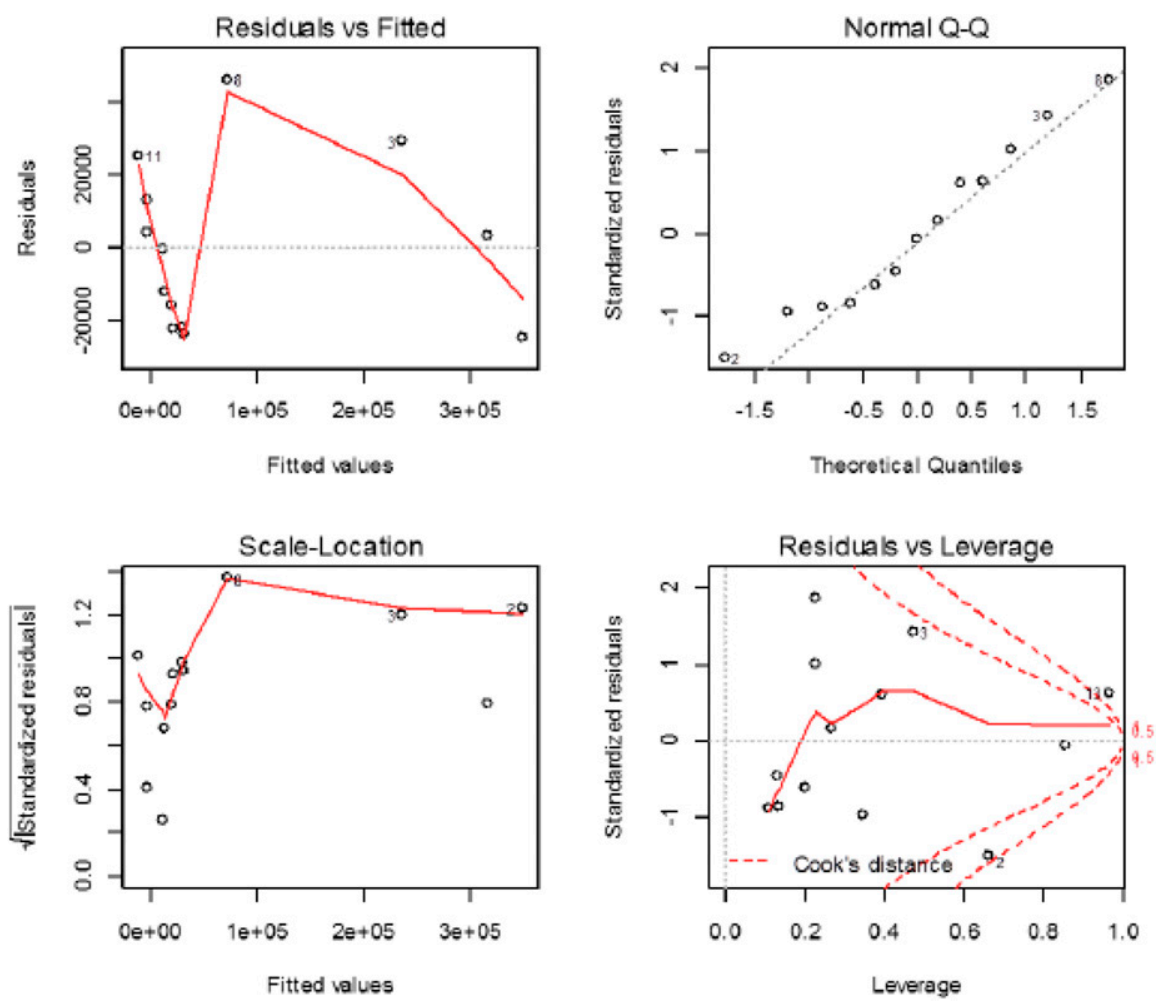

Fig. 2. Plot for the analysis of residuals for model 2. Relationship between income and the corporate social responsibility practices.

arguing that companies should favor a strategic approach to CSR - in other words, they should identify the corporate agenda that can bring the greatest competitive benefit.

According to the procedure, the best model is the one with the explanatory variables of work, environment, and territory only.

After estimating the model's parameters and verifying the hypotheses, we then proceeded with an analysis of the residues to verify that the basic hypotheses on the errors were valid. In Fig. 2, the graph of the analysis of model 2 can be observed.

Moving on to check the various hypotheses on accidental errors, we can observe the following:

- The first quadrant (top left) is the hypothesis of error independence. In this case, it seems the errors follow an abnormal behavior. Therefore, this hypothesis is accepted with due precaution.

- The second quadrant (top right) is the hypothesis of error normality. In this case, the points seem to be placed in the immediate vicinity of the dotted line, even if some of them are not exactly coincident.

- The third quadrant (bottom left) is the hypothesis of homoskedasticity. In this case, the points do not seem to be very scattered. Therefore, this hypothesis is accepted with due precaution.

- The fourth quadrant (bottom right) is the anomalous data. In this case, they seem rather grouped and there are no particular values out of the scheme.
In general, the hypothesis of the normality of errors seems to have been respected, but the hypotheses of independence and homoskedasticity, which do not seem to be respected, should be taken into consideration.

In summary, in model 1, we see how added value is statistically influenced by work-related CSR practices. This means that by investing in their employees, companies involved in the agri-food sector can increase the added value of their products, as demonstrated by Becchetti et al. (2014), Luhmann and Theuvsen (2016), and Romani et al. (2016). This takes place with a CSR strategy aimed at increasing workplace safety, promoting equal opportunities, and investing resources in employee training. Brammer and Millington (2004) and Jean et al. (2018) perceive that companies should take a deeper responsibility to ensure greater benefits.

In model 2, the results show that the operating result can be improved by CSR practices in the areas of work, environment, and territory.

Through this study, we found a link between CSR and the economic performance of companies operating in the agri-food sector. The results of multiple regression models show that companies that invest in social responsibility have an advantage in terms of added value and operating results. In particular, social strategies in terms of work, environment, and territory seem to be very important (Bechetti et al., 2014; Fafchamps and Minten, 2010). However, the product dimension does not seem to affect economic performance, and perhaps this is a result of problems related to the quality and information that distinguish agri-food products. CSR is increasingly valued as an aspect to contribute to developing company sustainability (Jean et al., 2018). Based on our results, the research hypothesis initially formulated is partially supported, as some variables contribute more than others to CSR. As shown in other studies (e.g., Luhmann and Theuvsen, 2016; Romani et al., 2016) in the globalized economy, achieving a competitive advantage by adopting CSR practices allows firms to remain in the market. On the consumer demand side, even if adopting CSR practices does not influence all consumers, in economies with high per-capita income, this represents a very interesting market segment.

\section{Conclusions and Implications}

Based on this study, it has been shown that the added value of agri-food companies seems to be statistically influenced by CSR practices in the field of work. This important first result shows that, by investing in equal opportunities and the safety and training of their employees, companies involved in the agri-food sector can increase the added value of their products. Therefore, the adoption of CSR practices has positive effects, i.e., an intangible investment that takes the form of greater added value for the company. The study shows that social responsibility allows you to meet the expectations of the entrepreneur and the social partners. The practices of social responsibility favor organizational models of cohesion and they go in the right direction of the company mission and in respect of the environment where the company is part. In fact, if the goal of the company is added value, the research in question highlights that it is achieved. Not a minor aspect is the cohesion that is created in the workplace and the good business practices that create positive externalities for all the actors involved in the company production. In addition, this means that for organizations to contribute to improving CSR and global sustainability, they must undertake an internal transition process of adaptation and flexibility, which should involve all stakeholders and be in line with a long-term strategic view. Organizations in an AFS must therefore implement sustainable and CSR strategies as an integral part of their growth and competitiveness strategy, as a way to maximize their resources and have a positive impact on their performance.

These results also show how a CSR strategy should be a natural orientation for agri-food companies because it can improve economic performance and thus win the competitive challenge with national and international competitors.

For all these reasons, despite the complexities and challenges of a CSR strategy, it represents the winning element that contributes to the growth and social and economic development of companies, the people who collaborate within them, the local community to which they belong, the country of 
operation and, ultimately, all society and the world economy. As shown by Becchetti et al. (2014), companies traditionally oriented to profit maximization can also attenuate the social and environmental externalities of their action.

A company operating in a given system is called upon to respond to the expectations of its social partners. Well the study shows that the expectations are met and that it is possible to create those conditions of growth and development of the territory in general at the microeconomic and macroeconomic levels.

This study also makes some contributions to theory and practice. Regarding contributions to theory, advancing knowledge for the literature on CSR stands out, as well as the subject of sustainability. In the practical domain, it is believed this study can help researchers and managers to identify potential strengths and weaknesses in the formulation and implementation of their CSR practices, to understand what their strategic position is, and the strategy they should follow. Second, the empirical results allowed construction of an innovative framework, providing an orientation for organizations to follow in their economic performance for them to become successful and sustainable. It contributes also to highlighting that when organizations adopt strategies directed toward CSR, this means all stakeholders feel involved in the process, which gives legitimacy to and awareness of the responsibilities assumed by their managers.

Finally, this study highlights the role of CSR, which has increasingly become a variable strategy of success for companies in the global market. The study is relevant for agrifood companies operating in their local areas. The adoption of CSR practices favors processes of value creation and implements the company's role in the territory as a tool for development. As the implementation of CSR practices was shown to have a positive impact on economic performance, management should treat CRS as a core business strategy, which could pave the way to a firm's perpetual growth.

\section{Literature Cited}

Armstrong, J.S. and T.S. Overton. 1977. Estimating nonresponse bias in mail surveys. J. Mktg. Res. 14(3):396-402.

Becchetti, L., L. Bruni, and S. Zamagni. 2014. Microeconomia: Un testo di economia civile. Il Mulino, Bologna, Italy.
Becker-Olsen, K.L., B.A. Cudmore, and R.P. Hill. 2006. The impact of perceived corporate social responsibility on consumer behavior. J. Bus. Res. 59(1):46-53.

Belletti, G., A. Marescotti, J. Sanz-Cañada, and H. Vakoufaris. 2015. Linking protection of geographical indications to the environment: Evidence from the European Union olive-oil sector. Land Use Policy 48:94-106.

Belu, C. and C. Manescu. 2013. Strategic corporate social responsibility and economic performance. Appl. Econ. 45(19):2751-2764.

Blumberg, B.F., D.R. Cooper, and P.S. Schindler. 2005. Survey research, p. 243-276. Business research methods. McGraw-Hill, London.

Bowen, H.R. and F.E. Johnson. 1953. Social responsibility of the businessman. Harper, New York.

Brammer, S. and A. Millington. 2004. Stakeholder pressure, organizational size, and the allocation of departmental responsibility for the management of corporate charitable giving. Bus. Soc. 43(3):268-295.

Bruno, N. 2013. Introduzione alla statistica descrittiva con R. Università di Parma, Parma, Italy.

European Union Commission. 2003. Commission recommendation of 6 May 2003 concerning the definition of micro, small and medium-sized enterprises. Official J. Eur. Union 46(L124):36-41.

Fafchamps, M. and B. Minten. 2001. Social capital and agricultural trade. Amer. J. Agr. Econ. 83(3):680-685.

Gaviglio, A., M. Bertocchi, M.E. Marescotti, E. Demartini, and A. Pirani. 2016. The social pillar of sustainability: A quantitative approach at the farm level. Agr. Food Econ. 4(1):15.

Hartmann, M. 2011. Corporate social responsibility in the food sector. Eur. Rev. Agr. Econ. 38(3):297-324.

Hotelling, H. 1933. Analysis of a complex of statistical variables into principal components. J. Educ. Psychol. 24(6):417-441.

Jean, A.T., X. Wang, and S. Suntu. 2018. Corporate social responsibility in Madagascar: An investigation on Chinese companies. Intl. J. Construction Mgt. 1-10. doi: 10.1080/15623599.2018.1462442.

Kitzmueller, M. and J. Shimshack. 2012. Economic perspectives on corporate social responsibility. J. Econ. Lit. 50(1):51-84.

Lancaster, K.J. 1966. A new approach to consumer theory. J. Polit. Econ. 74(2):132-157.

Lockett, A., J. Moon, and W. Visser. 2006. Corporate social responsibility in management research: Focus, nature, salience and sources of influence. J. Mgt. Stud. 43(1):115-136.

Luhmann, H. and L. Theuvsen. 2016. Corporate social responsibility in agribusiness: Literature review and future research directions. J. Agr. Environ. Ethics 29(4):673-696.

Maloni, M.J. and M.E. Brown. 2006. Corporate social responsibility in the supply chain: An application in the food industry. J. Bus. Ethics 68(1):35-52.
Margolis, J.D. and J.P. Walsh. 2003. Misery loves companies: Rethinking social initiatives by business. Adm. Sci. Q. 48(2):268-305.

Maroušek, J., S. Hašková, R. Zeman, and R. Vaníčková. 2014. Managerial preferences in relation to financial indicators regarding the mitigation of global change. Sci. Eng. Ethics 21(1):203-207.

Mineo, A. 2004. Modelli lineari e non lineari in R. Department of Statistical and Mathematical Sciences, University of Palermo.

Mohr, L.A. and D.J. Webb. 2005. The effects of corporate social responsibility and price on consumer responses. J. Consum. Aff. 39(1):121147.

Orlitzky, M., F.L. Schmidt, and S.L. Rynes. 2003. Corporate social and financial performance: A meta-analysis. Organ. Stud. 24(3):403-441.

Porter, M.E. and M.R. Kramer. 2006. Strategy and society: The link between competitive advantage and corporate social responsibility. Harvard Bus. Rev. December:78-92.

Quiñones-Ruiz, X.F., M. Penker, G. Belletti, A. Marescotti, S. Scaramuzzi, E. Barzini, M. Pircher, F. Leitgebt, and L.F. Samper-Gartner. 2016. Insights into the black box of collective efforts for the registration of geographical indication. Brit. Food J. 57:103-116.

R Core Team. 2013. A language and environment for statistical computing.

Romani, S., S. Grappi, and R.P. Bagozzi. 2016 Corporate socially responsible initiatives and their effects on consumption of green products. J. Bus. Ethics 135(2):253-264.

Siegel, D.S. and D.F. Vitaliano. 2007. An empirical analysis of the strategic use of corporate social responsibility. J. Econ. Mgt. Strategy 16:773792.

Smith, V. and P. Langford. 2009. Evaluating the impact of corporate social responsibility programs on consumers. J. Mgt. Organ. 15(1):97109.

Tregear, A., A. Török, and M. Gorton. 2016. Geographical indications and upgrading of small-scale producers in global agro-food chains: A case study of the Makó onion protected designation of origin. Environ. Plann. A 48(2):433-451.

Vlachos, P.A., A. Tsamakos, A.P. Vrechopoulos, and P.K. Avramidis. 2009. Corporate social responsibility: Attributions, loyalty, and the mediating role of trust. J. Acad. Mktg. Sci. 37(2):170-180.

Wang, Y.G., W.H. Hsu, and K.W. Chang. 2012. The impact of fulfilling corporate social responsibility on firm performance: Stakeholder's approach. Intl. J. Modelling Sim. 32(3):206-215.

Zamagni, S. 2013. Impresa socialmente responsabile e mercato civile, Bologna. Il Mulino.

Zeithaml, V.A. 1988. Consumer perceptions of price, quality, and value: A means-end model and synthesis of evidence. J. Mktg. 52(3):2-22. 